Pacific Journal of Mathematics

THE PRINCIPLE OF SUBORDINATION APPLIED TO 


\section{THE PRINCIPLE OF SUBORDINATION APPLIED TO FUNCTIONS OF SEVERAL VARIABLES}

\section{T. J. SUFFrIDGE}

In this paper we consider univalent maps of domains in $C^{n}(n \geqq 2)$. Let $P$ be a polydisk in $C^{n}$. We find necessary and sufficient conditions that a function $f: P \rightarrow C^{n}$ be univalent and map the polydisk $P$ onto a starlike or a convex domain. We also consider maps from

$$
\begin{aligned}
D_{p} & =\left\{z:|z|_{p}<1\right\} \subset C^{n} \\
|z|_{p} & =\left|\left(z_{1}, z_{2}, \cdots, z_{n}\right)\right|_{p}=\left[\sum_{j=1}^{n}\left|z_{j}\right|^{p}\right]^{1 / p}, \quad p \geqq 1
\end{aligned}
$$

into $C^{n}$ and give necessary and sufficient conditions that such a map have starlike or convex image.

In [4] Matsuno has considered a similar problem for the hypersphere $D_{2} \subset C^{n}$. His definition of starlikeness is different from that used in this paper, but the results show that the two definitions are equivalent. However, his definition of convex-like is not equivalent to geometrically convex.

1. Preliminary lemmas. For $\left(z_{1}, z_{2}, \cdots, z_{n}\right)=z \in C^{n}$, define $|z|=$ $\max _{1 \leqq j \leqq n}\left|z_{j}\right|$. Let $E_{r}=\left\{z \in C^{n}:|z|<r\right\}$ and $E=E_{1}$. Let $\mathscr{P}$ be the class of mappings $w: E \rightarrow C^{n}$ which are holomorphic and which satisfy $w(0)=0, \operatorname{Re}\left[w_{j}(z) / z_{j}\right] \geqq 0$ when $|z|=\left|z_{j}\right|>0,(1 \leqq j \leqq n)$ where $w=$ $\left(w_{1}, w_{2}, \cdots, w_{n}\right)$. The following lemmas are generalizations of Theorems $A$ and $B$ of Robertson [5, p. 315-317].

LeMma 1. Let $v(z ; t): E \times I \rightarrow C^{n}$ be holomorphic for each $t \in I=$ $[0,1], v(z ; 0)=z, v(0, t)=0$ and $|v(z ; t)|<1$ when $z \in E$. If

$$
\lim _{t \rightarrow 0^{+}}\left[(z-v(z ; t)) / t^{\rho}\right]=w(z)
$$

exists and is holomorphic in $E$ for some $\rho>0$, then $w \in \mathscr{P}$.

Proof. The hypothesis (2) implies that $\lim _{t \rightarrow 0^{+}} v_{j}(z ; t)=z_{j}$ (here $v(z ; t)=\left(v_{1}(z ; t), v_{2}(z ; t), \cdots, v_{n}(z ; t)\right)$ so

$$
\frac{2 z_{j}\left(z_{j}-v_{j}(z ; t)\right)}{z_{j}+v_{j}(z ; t)} \equiv \psi_{j}(z ; t)
$$

is holomorphic for $z \in E, z_{j} \neq 0 \quad(1 \leqq j \leqq n)$. By Schwarz lemma, $|v(z ; t)| \leqq|z|$ and hence $\operatorname{Re}\left[\psi_{j}(z ; t) / z_{j}\right] \geqq 0$ when $|z|=\left|z_{j}\right|>0$. Setting $\psi(z ; t)=\left(\psi_{1}, \psi_{2}, \cdots, \psi_{n}\right),\left(z \in E, z_{1} z_{2} \cdots z_{n} \neq 0\right)$ we observe that 


$$
\lim _{t \rightarrow 0^{+}} \psi(z ; t) / t^{\rho}=w(z)
$$

for these values of $z$ and using continuity of $w$ we conclude $w \in \mathscr{P}$.

Lemma 2. Let $f: E \rightarrow C^{n}$ be holomorphic and univalent and satisfy $f(0)=0$. Let $F(z ; t): E \times I \rightarrow C^{n}$ be a holomorphic function of $z$ for each $t \in I=[0,1], F(z ; 0)=f(z), F(0, t)=0$ and suppose $F(z ; t) \prec f$ for each $t \in I$ (i.e., $F(E ; t) \subset f(E)$ for each $t \in I)$. Let $\rho>0$ be such that $\lim _{t \rightarrow 0^{+}} F(z ; 0)-F(z ; t) / t^{\rho}=F(z)$ exists and is holomorphic. Then $F(z)=J w$ where $w \in \mathscr{P}$. Here $F$ and $w$ are written as column vectors and $J$ is the complex Jacobian matrix for the mapping $f$.

Proof. Since $F(z ; t) \prec f$ for each $t \in I$, there exists $v: E \times I \rightarrow E$ such that $f(v(z ; t))=F(z ; t)$ where $|v(z ; t)| \leqq|z|$. Writing $f$ as a column vector we have $f(v(z ; t))=f(z)+J(v(z ; t)-z)+R(v(z ; t), z)$ where $|R(\zeta, z)| /|\zeta-z| \rightarrow 0$ as $|\zeta-z| \rightarrow 0$. Hence

$$
\frac{F(z ; 0)-F(z ; t)}{t^{\rho}}=J\left(\frac{z-v(z ; t)}{t^{\rho}}\right)-\frac{R(v(z ; t), z)}{t^{\rho}}
$$

and the lemma follows from Lemma 1.

2. Starlike and convex mappings of the polydisk.

Definition. A holomorphic mapping $f: E \rightarrow C^{n}$ is starlike if $f$ is univalent, $f(0)=0$ and $(1-t) f \prec f$ for all $t \in I$.

THeOREM 1. Suppose $f: E \rightarrow C^{n}$ is starlike and that $J$ is the complex Jacobian matrix of $f$. There exists $w \in \mathscr{P}$ such that $f=J w$ where $f$ and $w$ are written as column vectors.

Proof. Apply Lemma 2 with $F(z ; t)=(1-t) f(z)$. Then

$$
f(z)=\lim _{t \rightarrow 0^{+}} \frac{f(z)-(1-t) f(z)}{t}=\lim _{t \rightarrow 0^{+}} \frac{F(z ; 0)-F(z ; t)}{t}
$$

and the theorem follows from Lemma 2.

We now consider the conclusion of Theorem 1 in component form. Let $J_{j}$ be the matrix obtained by replacing the $j$ th column in $J$ by the column vector $f, 1 \leqq j \leqq n$. Then the $j$ th component $w_{j}$ of $w$ is $\operatorname{det}\left(J_{j}\right) / \operatorname{det} J$. Theorem 1 therefore says that if $f$ is starlike then $\operatorname{Re}\left[\operatorname{det}\left(J_{j}\right) / z_{j} \operatorname{det} J\right] \geqq 0$ when $|z|=\left|z_{j}\right|>0$. Also,

$$
f_{j}=\frac{\partial f_{j}}{\partial z_{1}} w_{1}+\frac{\partial f_{j}}{\partial z_{2}} w_{2}+\cdots+\frac{\partial f_{j}}{\partial z_{n}} w_{n}, \quad 1 \leqq j \leqq n
$$


and equating coefficients in the power series using (3) we find

$$
w_{j}(z)=z_{j}+\text { terms of total degree } 2 \text { or greater } .
$$

Now suppose $\left|z^{(0)}\right|=\left|z_{j}^{(0)}\right|>0$ and let $\alpha_{k},(1 \leqq k \leqq n)$ be such that $z_{k}^{(0)}=$ $\alpha_{k} z_{j}^{(0)}$. Then $\left|\alpha_{k}\right| \leqq 1,(1 \leqq k \leqq n)$. Consider $w_{j}(z) / z_{j}=u\left(z_{j}\right)$ where $z$ is restricted to the set,

$$
z=\left(\alpha_{1}, \alpha_{2}, \cdots, \alpha_{n}\right) z_{j}, \quad\left|z_{j}\right|<1 .
$$

Then $\operatorname{Re} u\left(z_{j}\right) \geqq 0,0<\left|z_{j}\right|<1$ and $u\left(z_{j}\right) \rightarrow 1$ as $z_{j} \rightarrow 0$. Since $\operatorname{Re} u\left(z_{j}\right)$ is a harmonic function of $z_{j}$, we conclude $\operatorname{Re} u\left(z_{j}\right)>0,\left|z_{j}\right|<1$ and

$$
\operatorname{Re}\left[w_{j}(z) / z_{j}\right]>0 \text { when }|z|=\left|z_{j}\right|>0 .
$$

We now prove the converse of Theorem 1 .

Theorem 2. Suppose $f: E \rightarrow C^{n}$ is holomorphic, $f(0)=0, J$ is nonsingular and that

$$
f(z)=J w, w \in \mathscr{P} .
$$

Then $f$ is starlike.

Proof. Since det $J \neq 0$ when $z=0, f$ is univalent in a neighborhood of 0 . It is clear that $\left\{r: 0 \leqq r \leqq 1\right.$ and $f$ is univalent in $\left.E_{r}\right\}=A$ is a closed subset of $[0,1]$. We will show that $A$ is also open and that if $f$ is univalent in $E_{r}$ then $f\left(E_{r}\right)$ is starlike with respect to 0 .

Let $r>0$ be such that $f$ is univalent in $E_{r},(0<r<1)$. Let $z$ be fixed, $|z| \leqq r$ and let $v(z ; t)$ be such that $f(v(z ; t))=(1-t) f(z)$, $-\varepsilon<t<t_{0}$ where $\varepsilon$ is small and positive and $t_{0}>0$. This is possible since $\operatorname{det} J \neq 0$.

Then

$$
\begin{aligned}
v(z ; t) & =v(z ; 0)+J^{-1} \cdot(-f(z)) \cdot t+g(t) \\
& =z-J^{-1} \cdot J \cdot w \cdot t+g(t) \\
v(z ; t) & =z-t w+g(t)
\end{aligned}
$$

by (5). Here $|g(t)| / t \rightarrow 0$ as $t \rightarrow 0$. Using (4), we conclude $|v(z ; t)|$ is a strictly decreasing function of $t$. Hence each point of the ray $(1-t) f(z), 0<t \leqq 1$ is the image of a point $v(z ; t) \in E_{r}$ for each $z$ such that $|z| \leqq r$. We conclude that $f\left(E_{r}\right)$ is starlike with respect to 0 . We now show $A$ is open. Observe that $f$ is one-to-one in the closed polydisk $\bar{E}_{r}$ for if $|z| \leqq|\zeta|=r, z \neq \zeta$ and $f(z)=f(\zeta)$ then by (6) and (4) we can conclude that for $t$ positive and sufficiently small there are functions $v(\zeta ; t), v(z ; t)$ such that $v(\zeta ; t), v(z, t) \in E_{r}, v(\zeta ; t) \neq v(z ; t)$ and 
$f(v(z ; t))=(1-t) f(z)=(1-t) f(\zeta)=f(v(\zeta, t))$ which is a contradiction.

We now define a continuous nonnegative function $\phi: E \times E \rightarrow R$ ( $R$ is the real numbers) such that $\phi(z, \zeta)=0$ if and only if $f(z)=f(\zeta)$, $z \neq \zeta$. We show that $\phi$ is positive on the closed set $\bar{E}_{r} \times \bar{E}_{r}$ and hence has a positive minimum on this set. This will imply $f$ is univalent in $E_{r+\varepsilon}$ for some $\varepsilon>0$ and hence $A$ is open. For $z, \zeta \in E$, define $G(z, \zeta)=\operatorname{det}\left(a_{i j}\right)$ where

$$
a_{i j}=\left\{\begin{array}{l}
\frac{f_{i}\left(z_{1}, z_{2}, \cdots, z_{j}, \zeta_{j+1} \cdots, \zeta_{n}\right)-f_{i}\left(z_{1}, z_{2}, \cdots, z_{j-1}, \zeta_{j}, \cdots, \zeta_{n}\right)}{z_{j}-\zeta_{j}},\left(z_{j} \neq \zeta_{j}\right) \\
\frac{\partial f_{i}}{\partial z_{j}}\left(z_{1}, z_{2}, \cdots, z_{j}, \zeta_{j+1}, \cdots, \zeta_{n}\right), \quad\left(z_{j}=\zeta_{j}\right)
\end{array}\right.
$$

and $f=\left(f_{1}, f_{2}, \cdots, f_{n}\right)$.

Now set $\phi(z, \zeta)=|G(z, \zeta)|+\sum_{j=1}^{n}\left|f_{j}(z)-f_{j}(\zeta)\right|$. Then $\phi(z, z)=$ $\mid \operatorname{det}(J(z) \mid>0$ while

$$
\phi(z, \zeta)>0 \text { when } f(z) \neq f(\zeta) .
$$

If $f(z)=f(\zeta)$ for some $z, \zeta \in E, z \neq \zeta$ then the columns of $G(z, \zeta)$ are not linearly independent so $G(z, \zeta)=0$ and $\phi(z, \zeta)=0$. The proof is now complete.

Theorem 3. Suppose $f: E \rightarrow C^{n}$ is holomorphic, $f(0)=0$ and that $J$ is nonsingular for all $z \in E$. Then $f$ is a univalent map of $E$ onto a convex domain if and only if there exist univalent mappings $f_{j}(1 \leqq j \leqq n)$ from the unit disk in the plane onto convex domains in the plane such that $f(z)=T\left(f_{1}\left(z_{1}\right), f_{2}\left(z_{2}\right) \cdots, f_{n}\left(z_{n}\right)\right)$ where $T$ is a nonsingular linear transformation.

Proof. It is clear that if $f$ satisfies the conditions given in the theorem, then $f$ is univalent and $f(E)$ is convex. We will prove the converse.

Suppose $f$ is a univalent map of $E$ onto a convex domain. Let $A=\left(A_{1}, A_{2}, \cdots, A_{n}\right)$ where $A_{j} \geqq 0(1 \leqq j \leqq n)$ and let

$$
A_{t}(z)=\left(z_{1} e^{i A_{1} t}, z_{2} e^{i A_{2} t}, \cdots, z_{n} e^{i A_{n} t}\right)
$$

where $-1 \leqq t \leqq 1$. Then

$$
F(z ; t)=1 / 2\left[f\left(A_{t}(z)\right)+f\left(A_{-t}(z)\right)\right] \prec f \quad 0 \leqq t \leqq 1
$$

and $F(z ; t)$ satisfies the hypotheses of Lemma 2 with $\rho=2$. Usingthe same notation as in Lemma 2, we have 


$$
\begin{aligned}
F(z)= & \left(F_{1}, F_{2}, \cdots, F_{n}\right) \\
2 F_{j}= & \sum_{k=1}^{n} A_{k}^{2}\left(z_{k}^{2} \frac{\partial^{2} f_{j}}{\partial z_{k}^{2}}+z_{k} \frac{\partial f_{j}}{\partial z_{k}}\right) \\
& +2 \sum_{k=2}^{n} \sum_{l=1}^{k-1} A_{k} A_{l} z_{k} z_{l} \frac{\partial^{2} f_{j}}{\partial z_{l} \partial z_{k}}
\end{aligned}
$$

and also $F=J w, w \in \mathscr{P}$. Hence we find that $w_{j}=\operatorname{det} J^{(j)} / \operatorname{det} J$ where $J^{(j)}$ is obtained from $J$ by replacing the $j$ th column by $F$ written as a column vector. Fix $k, 1 \leqq k \leqq n$ and choose $A_{k}=1, A_{l}=0, l \neq k$, $1 \leqq l \leqq n$. Suppose $|z|=\left|z_{j}\right|>0, j \neq k$ and $z_{k}=0$. Then $w_{j} / z_{j}=0$ and since $\operatorname{Re}\left(w_{j} / z_{j}\right) \geqq 0$ when $|z|=\left|z_{j}\right|>0$ we must have $w_{j} \equiv 0$. We have therefore shown that for $1 \leqq j \leqq n$ and $1 \leqq k \leqq n$ we have

$$
z_{k}^{2} \frac{\partial^{2} f_{j}}{\partial z_{k}^{2}}+z_{k} \frac{\partial f_{j}}{\partial z_{k}}=\frac{\partial f_{j}}{\partial z_{k}} \psi_{k}
$$

where $\operatorname{Re}\left[\psi_{k}(z) / z_{k}\right] \geqq 0$ when $|z|=\left|z_{k}\right|>0$. With $k$ as before, fix $l$, $1 \leqq l \leqq n, l \neq k$ and choose $A_{k}=1, A_{l}=\varepsilon>0$ and $A_{m}=0,1 \leqq m \leqq n$, $m \neq k, l$.

Using (8) we conclude

$$
w_{j}=\varepsilon \frac{z_{k} z_{l} G_{j}}{\operatorname{det} J}+O\left(\varepsilon^{2}\right) \quad(j \neq k)
$$

where $G_{j}$ is obtained from $\operatorname{det} J$ by replacing the $j$ th column by the column $\partial^{2} f_{m} / \partial z_{l} \partial z_{k}(1 \leqq m \leqq n)$. Hence $\operatorname{Re}\left[z_{k} z_{l} / z_{j} \cdot G_{j} / \operatorname{det} J\right] \geqq 0$ when $|z|=\left|z_{j}\right|>0$. Since $\operatorname{Re}\left[z_{k} z_{l} / z_{j} \cdot G_{j} / \operatorname{det} J\right]=0$ when $z_{k} z_{l}=0$ we see that $G_{j} \equiv 0$ for each $j, 1 \leqq j \leqq n$.

Since the system of equations

$$
\sum_{j=1}^{n} \frac{\partial f_{m}}{\partial z_{j}} \dot{\phi}_{j}=\frac{\partial^{2} f_{m}}{\partial z_{l} \partial z_{k}} \quad 1 \leqq m \leqq n
$$

has solution

$$
\dot{\rho}_{j}=\frac{G_{j}}{\operatorname{det} J}=0 \quad 1 \leqq j \leqq n
$$

we conclude

$$
\frac{\partial^{2} f_{m}}{\partial z_{l} \partial z_{k}}=0 \quad 1 \leqq m \leqq n .
$$

This implies

$$
f_{m}(z)=\sum_{j=1}^{n} a_{j, m} \phi_{j, m}\left(z_{j}\right)
$$$$
1 \leqq m \leqq n
$$

where $\dot{\phi}_{j, m}$ is analytic on the unit disk in the complex plane. Using 
(8) we conclude $\phi_{j, m}=\phi_{j, k}(1 \leqq m, k \leqq n)$ provided the constants $a_{j, m}$ in (9) are appropriately chosen. The theorem now follows readily from (8).

ExAMPle 1. Let $f: E \rightarrow C^{2}$ be given by $f(z)=\left(z_{1}+a z_{2}^{2}, z_{2}\right)$ where $a$ is a complex number, $a \neq 0$. Clearly $f$ is univalent. Letting $f=J w$, we find $w_{1}=z_{1}-a z_{2}^{2}, w_{2}=z_{2}$ so $f$ is starlike provided $|a|<1$. Note that Theorem 3 implies the suprising result that none of the sets $f\left(E_{r}\right)$ is convex $(1>r>0)$.

EXAMPLE 2. Let $f: E \rightarrow C^{2}$ be given by $f(z)=\left(z_{1} g(z), z_{2} g(z)\right), g: E \rightarrow$ $C$ where $g$ is holomorphic, $0 \notin g(E)$. Then $f=J w$ implies

$$
w_{1} / z_{1}=w_{2} / z_{2}=1+\left[z_{1} \frac{\partial g}{\partial z_{1}}+z_{2} \frac{\partial g}{\partial z_{2}}\right] / g
$$

and $f$ is starlike if and only if $\operatorname{Re}\left(w_{1}(z) / z_{1}\right) \geqq 0, z \in E$. Conversely, one can show that if $f: E \rightarrow C^{2}$ is holomorphic, $f=J w$ where $w \in \mathscr{P}$ and $w_{1} / z_{1}=w_{2} / z_{2}$ then there exists $g: E \rightarrow C, g$ holomorphic, $0 \notin g(E)$ such that (10) holds and $f=\left(\left(a_{1} z_{1}+a_{2} z_{2}\right) g,\left(b_{1} z_{1}+b_{2} z_{2}\right) g\right),\left(a_{1} b_{2} \neq a_{2} b_{1}\right)$. In these cases the intersection of the polydisk $E$ with an analytic plane $\alpha z_{1}+\beta z_{2}=0$ maps into an analytic plane $\delta f_{1}+\gamma f_{2}=0$. Interesting choices of $g$ are $g(z)=\left(1-z_{1} z_{2}\right)^{-1}$ and $g(z)=\left[\left(1-z_{1}\right)\left(1-z_{2}\right)\right]^{-1}$.

3. Extension to convex and starlike maps of $D_{p}$. Since the details of the proofs for the results in this section are similar to those in §'s 2 and 3, we omit the details. We wish to find lemmas which apply to $D_{p}\left(D_{p}\right.$ is defined in equation (1)) in the same way that Lemmas 1 and 2 apply to the polydisk. The crucial point is that given equation (6) with $0 \neq z \in D_{p}$ we wish to conclude

$$
|v(z ; t)|_{p} \leqq|z|_{p} \quad \text { when } \quad 0<t<\varepsilon
$$

for some $\varepsilon>0$. This will be true provided $\sum_{j=1}^{n}\left|z_{j}-t w_{j}\right|^{p}<\sum_{j=1}^{n}\left|z_{j}\right|^{p}$ for $t$ sufficiently small. That is

$$
\sum_{\substack{j=1 \\ z_{j} \neq 0}}^{n}\left|z_{j}\right|^{p}\left(1-2 t \operatorname{Re} w_{j} / z_{j}+t^{2}\left|w_{j} / z_{j}\right|^{2}\right)^{p / 2}+\sum_{z_{j}=0} t^{p}\left|w_{j}\right|^{p}<\sum_{j=1}^{n}\left|z_{j}\right|^{p}
$$

or

$$
t\left(\sum_{\substack{j=1 \\ z_{j} \neq 0}}^{n}-p \operatorname{Re}\left|z_{j}\right|^{p} \operatorname{Re}\left(w_{j} / z_{j}\right)+\sum_{z_{j}=0} t^{p-1}\left|w_{j}\right|\right)<0
$$

when $t$ is sufficiently small, $t>0$. Hence we define $\mathscr{P}_{p}$ for $p \geqq 1$ by $w \in \mathscr{P}_{p}$ if $w: D_{p} \subset C^{n} \rightarrow C^{n}, w(0)=0, w$ holomorphic and 


$$
\begin{aligned}
& \operatorname{Re} \sum_{j=1}^{n} w_{j} \cdot\left|z_{j}\right|^{p} / z_{j} \geqq 0 \quad \text { if } p>1 \\
& \operatorname{Re} \sum_{\substack{j=1 \\
z \\
z \neq 0}}^{n} w_{j} \cdot\left|z_{j}\right| / z_{j}-\sum_{z_{j}=0}\left|w_{j}\right| \geqq 0 \quad \text { if } p=1,
\end{aligned}
$$

$z \in D_{p}, w=\left(w_{1}, w_{2}, \cdots, w_{n}\right)$.

We now have the following lemmas and theorems which correspond to the lemmas and theorems of $\S \S 2$ and 3 .

Lemma 3. Let $v(z ; t): D_{p} \times I \rightarrow C^{n}$ be holomorphic for each $t \in I$, $v(z, 0)=z, v(0, t)=0$ and $|v(z ; t)|_{p}<1$ when $z \in D_{p}$. If

$$
\lim _{t \rightarrow 0^{+}}\left[(z-v(z ; t)) / t^{\rho}\right]=w(z)
$$

exists and is holomorphic in $D_{p}$ for some $\rho>0$, then $w \in \mathscr{P}_{p}$.

Lemma 4. Let $f: D_{p} \rightarrow C^{n}$ be holomorphic and univalent and satisfy $f(0)=0$. Let $F(z ; t): D_{p} \times I \rightarrow C^{n}$ be a holomorphic function of $z$ for each $t \in I, F(z, 0)=f(z), F(0 ; t)=0$ and suppose $F(z ; t) \prec f$ for each $t \in I$. Let $\rho>0$ be such that $\lim _{t \rightarrow 0^{+}}(F(z ; 0)-F(z ; t)) / t^{\rho}=F(z)$ exists and is holomorphic. Then $F(z)=J w$ where $w \in \mathscr{P}_{p}$.

Theorem 4. If $f: D_{p} \rightarrow C^{n}$ is starlike then there exists $w \in \mathscr{P}_{p}$ such that $f=J w$. Conversely, if $f: D_{p} \rightarrow C^{n}, f(0)=0, J$ is nonsingular and $f=J w, w \in \mathscr{P}_{p}$ then $f$ is starlike.

Theorem 5. Let $f: D_{p} \rightarrow C^{n}, f(0)=0$ and suppose $J$ is nonsingular. Then $f\left(D_{p}\right)$ is convex if and only if $F=J w$ where $w \in \mathscr{P}_{p}$ for each choice of $A=\left(A_{1}, A_{2}, \cdots, A_{n}\right), A_{j} \geqq 0(1 \leqq j \leqq n)$ and $F$ is given by (7) with $z \in D_{p}$.

Now set $p=2$. It is easy to see that Theorem 4 above is equivalent to Matsuno's Theorem 1 [4, p. 91]. Consider $f: D_{2} \rightarrow C^{2}$ given by $f(z)=\left(z_{1}+a z_{2}^{2}, z_{2}\right)$. Theorem 5 shows that $f\left(D_{2}\right)$ is convex if and only if $|a| \leqq 1 / 2$ while Matsuno's Lemma 3 [4, p. 94] implies $f$ is convexlike if and only if $|a| \leqq 3 \sqrt{3} / 4$. This shows that convex-like is not equivalent to geometrically convex.

\section{REFERENCES}

1. S. Bergman, The kernel function and conformal mapping, Mathematical Surveys, Vol. V., Amer. Math. Soc., New York, 1950.

2. S. Bochner and W. T. Martin, Several complex variables, Princeton Univ. Press, 1948. 
3. R. Gunning and H. Rossi, Analytic functions of several complex variables, PrenticeHall, Englewood Cliffs, N. J., 1965.

4. Takeshi Matsuno, Star-like theorems and convex-like theorems in the complex vector space, Sci. Rep. Tokyo, Kyoiku Daigaku, Sect. A 5 (1955), 88-95.

5. M. S. Robertson, Applications of the subordination principle to univalent functions, Pacific J. Math. 11 (1961), 315-324.

Received May 19, 1969. This research was supported by the National Science Foundation, Grant GP 8225.

UNIVERSITY OF KENTUCKY

LEXINGTON, KENTUCKY 


\section{PACIFIC JOURNAL OF MATHEMATICS}

\section{EDITORS}

H. SAMELSON

Stanford University

Stanford, California 94305

\section{RichaRd PIERCe}

University of Washington

Seattle, Washington 98105
J. DUGUNDJI

Department of Mathematics

University of Southern California

Los Angeles, California 90007

RICHARD ARENS

University of California

Los Angeles, California 90024

\section{ASSOCIATE EDITORS}

E. F. BECKENBACH

B. H. NeUManN

F. WOLF

K. YosHIDA

\section{SUPPORTING INSTITUTIONS}

UNIVERSITY OF BRITISH COLUMBIA CALIFORNIA INSTITUTE OF TECHNOLOGY UNIVERSITY OF CALIFORNIA MONTANA STATE UNIVERSITY

UNIVERSITY OF NEVADA

NEW MEXICO STATE UNIVERSITY

OREGON STATE UNIVERSITY

UNIVERSITY OF OREGON

OSAKA UNIVERSITY

UNIVERSITY OF SOUTHERN CALIFORNIA
STANFORD UNIVERSITY

UNIVERSITY OF TOKYO

UNIVERSITY OF UTAH

WASHINGTON STATE UNIVERSITY

UNIVERSITY OF WASHINGTON

${ }^{*} \quad{ }^{*} \quad{ }^{*}$
AMERICAN MATHEMATICAL SOCIETY
CHEVRON RESEARCH CORPORATION
TRW SYSTEMS
NAVAL WEAPONS CENTER




\section{Pacific Journal of Mathematics}

\section{Vol. 33, No. $1 \quad$ March, 1970}

Mir Maswood Ali, On some extremal simplexes ................... 1

Silvio Aurora, On normed rings with monotone multiplication........... 15

Silvio Aurora, Normed fields which extend normed rings of integers....... 21

John Kelly Beem, Indefinite Minkowski spaces..................... 29

T. F. Bridgland, Trajectory integrals of set valued functions ........... 43

Robert Jay Buck, A generalized Hausdorff dimension for functions and sets ......................................... 69

Vlastimil B. Dlab, A characterization of perfect rings . . . . . . . . . . . . 79

Edward Richard Fadell, Some examples in fixed point theory ............ 89

Michael Benton Freeman, Tangential Cauchy-Riemann equations and uniform approximation ............................. 101

Barry J. Gardner, Torsion classes and pure subgroups ................ 109

Vinod B. Goyal, Bounds for the solution of a certain class of nonlinear

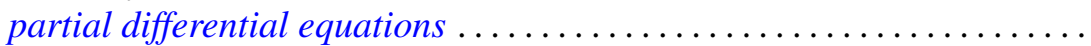

Fu Cheng Hsiang, On C, 1 summability factors of Fourier series at a given

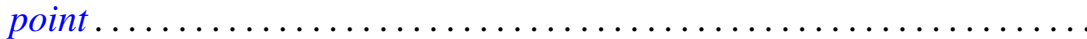

Lawrence Stanislaus Husch, Jr., Homotopy groups of PL-embedding

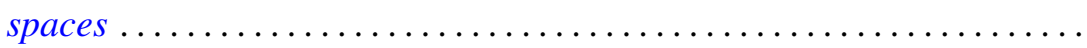

Daniel Ralph Lewis, Integration with respect to vector measures..........

Marion-Josephine Lim, $\mathscr{L}-2$ subspaces of Grassmann product spaces

Stephen J. Pierce, Orthogonal groups of positive definite multilinear functionals

W. J. Pugh and S. M. Shah, On the growth of entire functions of bounded index.

Siddani Bhaskara Rao and Ayyagari Ramachandra Rao, Existence of triconnected graphs with prescribed degrees . . .

Ralph Tyrrell Rockafellar, On the maximal monotonicity of subdifferential

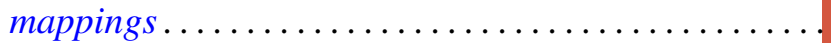

R. Shantaram, Convergence of a sequence of transformations of distribution functions. II ...............................

Julianne Souchek, Rings of analytic functions..............

Ted Joe Suffridge, The principle of subordination applied to functions of several variables...

Wei-lung Ting, On secondary characteristic classes in cobordism

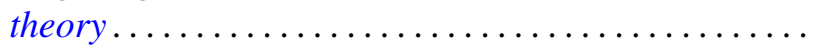

Pak-Ken Wong, Continuous complementors on $B^{*}$-algebras ...

Miyuki Yamada, On a regular semigroup in which the idempotents form a band. 